\title{
The Secular Enlightenment, Margaret C. Jacob
}

Princeton University Press. 2019. pp. 360

ISBN: 9780691161327; https://doi.org/10.2307/j.cdb2hnssx

\author{
Reviewed by Wessel Bentley \\ https://orcid.org/0000-0002-1167-4858 \\ University of South Africa \\ bentlw1@unisa.ac.za
}

The Enlightenment hailed a significant shift in our understanding of life, science, religion and meaning. In this book, Jacob scrutinises the effect of the Enlightenment on secular life. She points out that it would be a grave mistake to confine this period to only the spheres of science and religion; its impact caused a dynamic recalibration of how people experienced work, social spaces and even their sexuality. The understanding of time and punctuality, for instance, sparked by the personal ownership of clocks and watches, created an ordered and metered instrument that dictated the compartmentalising of personal and social activities. In our era, we cannot imagine a life without schedules, timeframes, public transport or even our own personal electronic devices - all of which are governed by time and timekeeping. To imagine the social impact this must have had on a population that mediated their days by virtue of general measures of time (where the sun is, what day it is, what season it is ...), is almost unimaginable. How does one then in religion, for example, distinguish between measured time and "God's time?" These and other questions are seldom discussed in literature that deals with the Enlightenment, and hence make this book an invaluable resource to dip one's toes in the complex emotional, rational and spiritual revolution that took place during this period.

Jacob then goes on to describe the impact of the Enlightenment on various cultures and regions, focusing specifically on the European context. She argues that the Enlightenment exacerbated social class distinctions and fuelled tensions between different sectors of society. It impacted cultures specifically in the use of diverse languages to express Enlightenment ideas; in turn challenging religious presuppositions that, up to this point, held sway in matters of truth and understanding. The religious monopoly on their held truth came under fire, and hence the social adherence to religion, particularly its stance on knowledge, cosmology and sexuality were being questioned by "ordinary" people. This was unheard of in the history of the church, and where it

\section{UNISA $\cong$}




\section{Bentley}

happened, these heretics were dealt with swiftly. The scale of this new questioning was beyond what the church or any holder of truth could manipulate or control.

Margaret Jacob is an excellent narrator of this period of human history. Her knowledge of these times is eloquently conveyed, opening up a new vista to the reader of an era that has been studied in detail, but with much less insight into the grassroots effects that were playing out. The use of illustrations, pictures and archived material plays a huge role in making this history a vivid portrayal of life on the streets of Europe.

I highly recommend this book to any person who seeks to gain some insight into the development of rational and critical thinking; especially as the Enlightenment was not so much a philosophy imposed from above, but was a groundswell of knowledge and questioning, mediated through scientific developments that were successfully communicated to the levels of understanding prevalent at this time.

This publication will, without doubt, become a fixture on the shelf of any person interested in the Enlightenment. 